\title{
Role of biochemical markers in type 2 diabetic patients of cataract and retinopathy attending Index Medical College, Hospital and Research Centre, Indore (M.P)
}

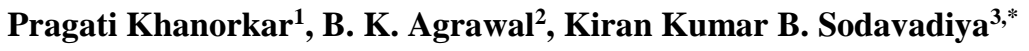 \\ ${ }^{1}$ P.G.Student, ${ }^{2}$ Professor and HOD, ${ }^{3}$ Assistant Professor, Dept. of Biochemistry, Index Medical College Hospital \\ and Research Centre, Indore (M.P) \\ *Corresponding Author: \\ Email: kb.sodavadiya@gmail.com
}

\begin{abstract}
Introduction: Aim of the study was to identify the role of selective serum lipids and serum creatinine in the development of type $2 \mathrm{DM}$ microvascular complications like cataract and retinopathy which are potential cause of blindness in these patients.

Materials and Methods: It is a cross sectional study of 100 patients, 50 each of cataract and retinopathy, compared with 50 healthy patients for lipid profile and serum creatinine by Erba 360 automated analyser. The study was carried out from Jan. 2016 to Jun.2017.

Result: In type 2 DM patients there is dyslipidemia i.e. raised levels of serum total cholesterol, triglycerides, low density and very low density lipoproteins and low levels of high density lipoproteins, when compared with the healthy subjects. When compared between cataract and retinopathy patients, serum total cholesterol, low density lipoproteins and LDL/HDL were significantly raised $(\mathrm{p}<0.001)$ in cataract patients whereas serum triglycerides $(\mathrm{p}<0.001)$ and serum creatinine $(\mathrm{p}<0.05)$ levels were significantly raised in retinopathy patients.

Conclusion: cataract and retinopathy are the preventable causes of blindness among the diabetic patients. Timely assessment of lipid profile and serum creatinine may help to detect these complications early and thus prevent the morbidity caused thereby.
\end{abstract}

Keywords: Cataract, Lipid profile, Retinopathy, Serum creatinine.

Received: $12^{\text {th }}$ October, 2017

\section{Introduction}

Diabetes is one of the most common noncommunicable diseases affecting almost $7 \%$ of the world's population. According to WHO 70 million people were affected by diabetes in India in the year 2015 and the figure is estimated to rise to 79.4 million by $2030 .{ }^{1}$ Diabetes Mellitus is a chronic metabolic disorder characterized by hyperglycaemia and disturbances in carbohydrate, fat and protein metabolism caused by defects in insulin secretion, action or both. ${ }^{2}$ There are mainly three types of diabetes: Type 1 diabetes, Type 2 diabetes including a related condition called pre-diabetes and gestational diabetes. The cause of type $2 \mathrm{DM}$ is multifactorial. The majority of persons with diabetes ( $90 \%)$ will have type 2 diabetes. Genetic susceptibility, environmental factors, physical activity, obesity, ethnicity, drugs and toxic agents, viral infection \& location play a crucial role in etiology and manifestation of type 2 DM complications. ${ }^{3}$ Diabetes has profound effects on the structure and function of many tissues and organs in the body. DM and its complications are among the world's most significant cause of morbidity and mortality. ${ }^{4}$
Diabetes increases the risk of many different complications that in general can be divided into macro- and microvascular disease. The macrovascular complications include coronary heart disease and cerebrovascular disease. The microvascular complications include neuropathy, nephropathy and diabetic retinopathy. ${ }^{5}$ Diabetics are about 15 times more likely to go blind than non-diabetics and this disease accounts to about $7 \%$ of the newly registered blind. Diabetic retinopathy is an important cause of blindness (about 80\%) and cataract formation which are the majority of the remaining $20 \%$. $^{6}$

Diabetic Retinopathy is the most common microvascular complication of diabetes, and a major cause of visual impairment worldwide. It is estimated that the global magnitude of DR will increase from 126.6 million in 2010 to 191 million by $2030 .^{7}$ Prevalence of Diabetes Mellitus is increasing rapidly in the developed countries and also in developing countries undergoing transition from traditional to modern lifestyle. ${ }^{8}$ Diabetic retinopathy (DR) is a microangiopathy affecting arterioles, capillaries and venules of the retina. It is characterized by increased vascular permeability, ocular haemorrhages, lipid exudate and development of 
new vessels on the retina and the posterior vitreous surface. ${ }^{4}$ Retinopathy is divided into two main categories: non-proliferative retinopathy and proliferative retinopathy. ${ }^{9}$ The nonproliferative DR is characterised by microaneurysms, hard yellow exudates, cotton wool spots, and venous beading. Proliferaive DR is characterised by NVD (neovascularisation on the disc), NVE (neovascularisation elsewhere). ${ }^{4}$ Hyperglycemia in diabetic patients causes a sequence of events leading to vascular endothelial dysfunction. These metabolic pathways include ${ }^{4}$

1. Increased polyol,

2. Protein kinase $\mathrm{C}(\mathrm{PKC})$ pathway activity,

3. Upregulation of growth factors of which vascular endothelial growth factor (VEGF),

4. Generation of advanced glycation end products (AGEs),

5. Chronic oxidative damage,

6. Chronic inflammation and abnormal clumping of leukocytes (leukostasis).

All these pathways cause inflammation, elevation of nitric oxide synthase leading to VEGF secretion and neovascularisation resulting in pathogenesis and progression of DR. ${ }^{4}$

The other cause of blindness as a proportion of total blindness are cataract $(47.8 \%) .{ }^{10}$ Cataract is the opacification of the earlier transparent lens protein fibres commonly seen as senile degenerative change. Diabetic cataract is considered a complication of DM, which affect individuals at younger ages and 2-5 times more frequently than healthy subjects. ${ }^{11}$ Cataract formation in diabetics seems to be related to the hyperglycemia or to hastened senile lens opacity. A snowflake like cataract occurs commonly in patients with diabetes and is more prone to progress than others. Several pathogenetic mechanisms that may precipitate formation of diabetic cataract are as follow. ${ }^{4}$

1. Increased osmotic stress caused by activation of the polyol pathway,

2. Non-enzymatic glycation of lens proteins, and

3. Increased oxidative stress.
All these factors cause liquefaction of the lens protein fibres and increased apoptotic activity of lens fibres leading to opacification of lens i.e cataract. ${ }^{4}$

Both diabetic retinopathy and cataract are among the preventable blindness. Dyslipidemia, nephropathy are implicated in the pathogenesis of DM complications but there is no consistent data suggesting their role in retinopathy or cataract development and hence our study was carried out to find out their role in these vision threatening complications.

\section{Materials and Methods}

On approval from ethical committee, this cross-sectional study was conducted from Jan. 2016 to Jun. 2017. 100 diabetic subjects 50 each of retinopathy and cataract and 50 healthy age and sex matched subjects were analysed for the study. The age group is 40-70 years for both sexes and clinically proven cases of diabetes with diabetic cataract and diabetic retinopathy attending ophthalmology OPD, Index Medical College and Hospital, Indore were taken as cases. Non-diabetic cases, Diabetics with other complications such as neuropathy, nephropathy, hypertension and other vascular complications, Diabetic patients with any other concurrent chronic disease such as cardiac diseases, thrombotic stroke etc., Gestational diabetes mellitus were excluded from the cases group. 50 age and sex matched normal, physically healthy volunteers, with no history of diabetes mellitus or any other chronic diseases were included in control group.

All subjects were analysed for fasting blood glucose, post prandial blood glucose, HbA1c, serum total cholesterol, serum triglycerides, serum low density lipoproteins, serum very low density lipoproteins, serum high density lipoproteins and serum creatinine. The analysis was done by ERBA 360 automated analyser and results were recorded. Parameters were estimated for methods as follows:

\begin{tabular}{|c|l|l|}
\hline S. No. & \multicolumn{1}{|c|}{ Parameter } & \multicolumn{1}{|c|}{ Method } \\
\hline 1. & HbA1C & $\begin{array}{l}\text { Kit based on immunoturbidimetry } \\
\text { method }^{150}\end{array}$ \\
\hline 2. & Blood Glucose & $\begin{array}{l}\text { Enzymatic method- Glucose Oxidase } \\
\text { and Peroxidase- End point }^{151}\end{array}$ \\
\hline 3. & Serum creatinine & Modified kinetic method of Jaffe 152 \\
\hline 4. & Serum cholesterol & $\begin{array}{l}\text { Enzymatic cholesterol oxidase and } \\
\text { peroxide - End point method }\end{array}$ \\
\hline 5. & HDL & Modified PEG method \\
\hline 6. & Serum Triglycerides & GPO- Trinder method \\
\hline 7. & Serum LDL & using Friedwald formula \\
\hline
\end{tabular}




\begin{tabular}{|c|l|l|}
\hline & & LDL $=$ TC $-(\mathrm{HDL}+\mathrm{TG} / 5)$ \\
\hline 8. & Serum VLDL & $\begin{array}{l}\text { Using Friedewald equation } \\
\text { VLDL }=1 / 5 \text { TG level (that is TG /5) }\end{array}$ \\
\hline
\end{tabular}

\section{Result}

Biochemical parameters were presented as Mean. Categorical variables were expressed in actual numbers and percentage. The biochemical parameters were also compared between the groups by one-way ANOVA test using SPSS 20 software.

$\mathrm{p}<0.05$ was taken as significant $(\mathrm{S})$

$\mathrm{p}<0.001$ was taken as highly significant(HS)

$\mathrm{p}>0.05$ was taken as non-significant (NS).

In present study, maximum number of patients are in the age group of 51-60 years i.e. for control $(50 \%)$, cataract $(38 \%)$ and retinopathy $(52 \%)$. Thus cases and controls are age matchedand the disease is commonly seen in elderly patients. Among the cases and controls $60 \%$ population is males and there is no significant association of sex and the disease.

With the increase in the duration of diabetes, there are more chances of retinopathy $(r=0.97)$, almost $40 \%$ of patients with diabetes have retinopathy with duration of DM of $>15$ years.
Whereas no such association is seen with cataract patients.

There is a strong association of fasting blood glucose $(\mathrm{p}<0.001)$, post meal blood glucose ( $\mathrm{p}$ $<0.001)$ and HbA1c (p <0.001) with the development of both cataract and retinopathy among diabetic patient when compared with controls as well as between cataract and retinopathy patients.

There is significant association of serum creatinine $(\mathrm{p}<0.05)$ with retinopathy development when compared with cataract group.

Among the diabetic patients there is positive association of total cholesterol $(\mathrm{p}<0.001)$, low density lipoprotein $(\mathrm{p}<0.001)$, and LDL/HDL $(p<0.01)$ for cataract patients when compared against the retinopathy group.

Among the diabetic patients there is positive association of serum triglycerides $(p<0.001)$ and very low density lipoproteins $(p<0.001)$ for retinopathy patients when compared against cataract group.

Table 1: Distribution of age among various groups

\begin{tabular}{|l|c|c|c|}
\hline Age in years & Cataract & Retinopathy & Control \\
\hline $41-50$ & $13(26 \%)$ & $14(28 \%)$ & $7(14 \%)$ \\
\hline $51-60$ & $19(38 \%)$ & $26(52 \%)$ & $25(50 \%)$ \\
\hline $61-70$ & $18(36 \%)$ & $10(20 \%)$ & $18(36 \%)$ \\
\hline Total & 50 & 50 & 50 \\
\hline Mean Age & 57.52 & 57.26 & 57.92 \\
\hline
\end{tabular}

Table 2: Association of duration of DM with disease

\begin{tabular}{|l|c|c|}
\hline \multicolumn{1}{|c|}{ Duration of DM in years } & Cataract & Retinopathy \\
\hline $1-5$ & 19 & 9 \\
\hline $6-10$ & 21 & 10 \\
\hline $11-15$ & 6 & 13 \\
\hline$>15$ & 4 & 18 \\
\hline Total & 50 & 50 \\
\hline
\end{tabular}

Table 3: Association of FBG, PMBG, HbA1c and Serum Creatinine among various groups

\begin{tabular}{|c|c|c|c|c|c|c|c|}
\hline Parameter & Group & Mean & F Value & p Value & $\begin{array}{c}\text { Multiple } \\
\text { Comparisons }\end{array}$ & q Value & p Value \\
\hline \multirow[t]{3}{*}{ FBG } & 1 & 98.5 & \multirow[t]{3}{*}{88.78} & \multirow[t]{3}{*}{$\mathrm{P}<0.001$} & 1 vs 2 & 8.62 & $\mathrm{p}<0.001$ \\
\hline & 2 & 144.4 & & & 1 vs 3 & 18.82 & $\mathrm{p}<0.001$ \\
\hline & 3 & 198.7 & & & 2 vs 3 & 10.2 & $\mathrm{p}<0.001$ \\
\hline \multirow[t]{3}{*}{ PMBG } & 1 & 117.8 & \multirow[t]{3}{*}{130.9} & \multirow[t]{3}{*}{$P<0.001$} & 1 vs 2 & 12.28 & $\mathrm{p}<0.001$ \\
\hline & 2 & 182.2 & & & 1 vs 3 & 22.86 & $\mathrm{p}<0.001$ \\
\hline & 3 & 237.7 & & & 2 vs 3 & 10.58 & $\mathrm{p}<0.001$ \\
\hline \multirow[t]{3}{*}{$\mathrm{HbA1c}$} & 1 & 5.37 & \multirow[t]{3}{*}{139.5} & \multirow[t]{3}{*}{$\mathrm{P}<0.001$} & 1 vs 2 & 16.14 & $\mathrm{p}<0.001$ \\
\hline & 2 & 7.64 & & & 1 vs 3 & 23.01 & $\mathrm{p}<0.001$ \\
\hline & 3 & 8.60 & & & 2 vs 3 & 6.87 & $\mathrm{p}<0.001$ \\
\hline Serum & 1 & 0.87 & 15.01 & $\mathrm{P}<0.001$ & 1vs 2 & 2.05 & NS \\
\hline
\end{tabular}




\begin{tabular}{|c|c|c|c|c|c|}
\hline \multirow[t]{2}{*}{ Creatinine } & 2 & 0.93 & 1 vs 3 & 7.45 & $p<0.001$ \\
\hline & 3 & 1.10 & 2 vs 3 & 5.45 & $\mathrm{p}<0.05$ \\
\hline
\end{tabular}

1- control, 2- cataract, 3- retinopathy

FBG- Fasting blood glucose, PMBG - Post meal blood glucose, HbA1c - Glycated haemoglobin

Table 4: Association of Lipid Profile among different groups

\begin{tabular}{|c|c|c|c|c|c|c|c|}
\hline Parameter & Group & Mean & F Value & p Value & $\begin{array}{c}\text { Multiple } \\
\text { Comparisons }\end{array}$ & q Value & p Value \\
\hline \multirow[t]{3}{*}{$\mathrm{TC}$} & 1 & 185.8 & \multirow[t]{3}{*}{315.2} & \multirow[t]{3}{*}{$\mathrm{P}<0.001$} & 1 vs 2 & 33.33 & $\mathrm{p}<0.001$ \\
\hline & 2 & 267.9 & & & 1 vs 3 & 27.29 & $p<0.001$ \\
\hline & 3 & 253 & & & $2 \mathrm{vs} 3$ & 6.04 & $p<0.001$ \\
\hline \multirow[t]{3}{*}{ TG } & 1 & 151.4 & \multirow[t]{3}{*}{112.3} & \multirow[t]{3}{*}{$\mathrm{p}<0.001$} & 1 vs 2 & 14.66 & $\mathrm{p}<0.001$ \\
\hline & 2 & 193.8 & & & 1 vs 3 & 20.99 & $P<0.001$ \\
\hline & 3 & 211 & & & 2 vs 3 & 5.92 & $\mathrm{p}<0.001$ \\
\hline \multirow[t]{3}{*}{ LDL } & 1 & 112.3 & \multirow[t]{3}{*}{230.3} & \multirow[t]{3}{*}{$\mathrm{p}<0.001$} & 1 vs 2 & 29.21 & $\mathrm{p}<0.001$ \\
\hline & 2 & 193.3 & & & 1 vs 3 & 21.74 & $p<0.001$ \\
\hline & 3 & 172.6 & & & 2 vs 3 & 7.47 & $p<0.001$ \\
\hline \multirow[t]{3}{*}{ HDL } & 1 & 43.2 & \multirow[t]{3}{*}{17.04} & \multirow[t]{3}{*}{$\mathrm{p}<0.001$} & 1 vs 2 & 8.08 & $p<0.001$ \\
\hline & 2 & 35.88 & & & 1 vs 3 & 5.5 & $p<0.001$ \\
\hline & 3 & 38.22 & & & 2 vs 3 & 2.58 & NS \\
\hline \multirow[t]{3}{*}{ VLDL } & 1 & 30.28 & \multirow[t]{3}{*}{111.6} & \multirow[t]{3}{*}{$\mathrm{p}<0.001$} & 1 vs 2 & 14.53 & $p<0.001$ \\
\hline & 2 & 38.7 & & & $1 \mathrm{vs} 3$ & 20.55 & $\mathrm{p}<0.001$ \\
\hline & 3 & 42.2 & & & 2 vs 3 & 6.06 & $\mathrm{p}<0.001$ \\
\hline \multirow[t]{3}{*}{ LDL/ HDL } & 1 & 2.65 & \multirow[t]{3}{*}{105.6} & \multirow[t]{3}{*}{$\mathrm{p}<0.001$} & 1 vs 2 & 19.86 & $\mathrm{p}<0.001$ \\
\hline & 2 & 5.52 & & & $1 \mathrm{VS} 3$ & 14.52 & $\mathrm{p}<0.001$ \\
\hline & 3 & 4.75 & & & 2 VS 3 & 5.35 & $\mathrm{P}<0.01$ \\
\hline
\end{tabular}

1- Control, 2- cataract, 3- retinopathy

TC- total cholesterol, TG- triglycerides, LDL- low density lipoproteins, VLDL- very low density lipoproteins, HDL- high density lipoproteins.

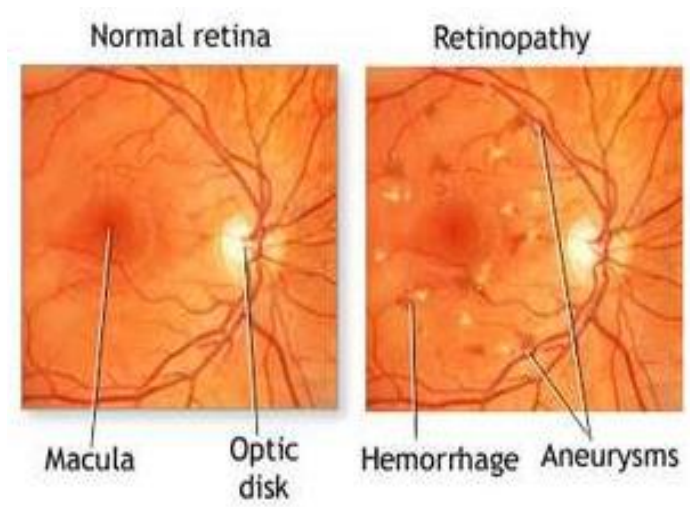

Fig.1: Diabetic Retinopathy changes

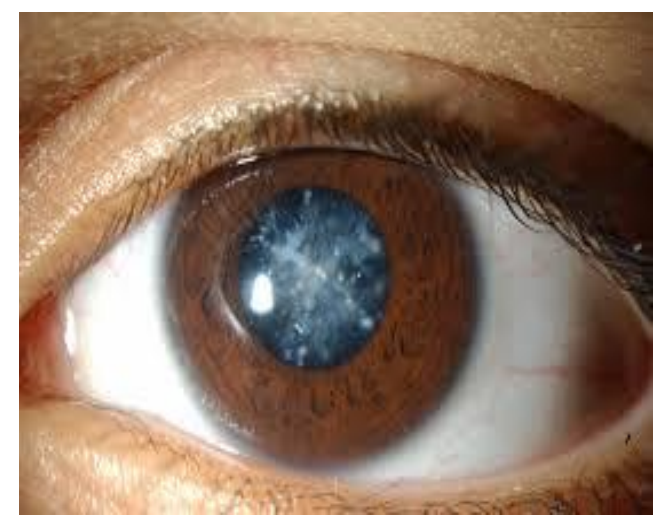

Fig. 2: Diabetic Snow Flake Cataract Discussion

Diabetes is emerging as a major noncommunicable disease responsible for morbidity and mortality worldwide. Diabetes shares the main burden of preventable blindness worldwide. Diabetic retinopathy and cataract are the main causes of visual impairment and blindness among the diabetics. ${ }^{12}$ Despite these two being preventable causes of blindness, a significant number of people from developing countries having PDR (Proliferative Diabetic 
Retinopathy) and DME (Diffuse macular edema) develop irreversible blindness. Lack of awareness of the disease sequelae is main cause of its asymptomatic course until the advanced sight-threatening stage. ${ }^{13}$

Present study shows, Maximum cases (26 of retinopathy and 19 of cataract) and controls (25) were found in the age group 51-60 years. While insulin resistance is common in older people, large numbers also have impaired insulin secretion. Age, body habitus and physical activity all play a role in the pathogenesis of hyperglycaemia associated with diabetes mellitus. Leptin levels relate to insulin resistance in older people and amylin secretion is associated with delayed return of glucose levels to baseline. ${ }^{14}$

In present study, the 5 year DM history has 19 patients with cataract, 5patients with retinopathy whereas with> 15 -year DM history has 4 patients with cataract, 20 patients with retinopathy. It shows the positive correlation of retinopathy with the duration of DM.

Similar observations were done by Davis et al, $1998,{ }^{15}$ Klein et al, $1984,{ }^{16}$ Katulanda et al, $2014 .{ }^{17}$

In the present study, we found a direct and significant association between retinopathy and FBG $(\mathrm{p}<0.001)$ and PMBG $(\mathrm{p}<0.001)$. Chronic hyperglycaemia is a most important factor for development of diabetic retinopathy ${ }^{18}$ and cataract $^{12,19,20}$ through polyol pathway, excessive formation of advanced glycosylated end products (AGEs), oxidative stress and activation of protein kinase-C.

In present study, serum triglycerides were significantly raised in cataract $(p<0.001)$, retinopathy $(\mathrm{p}<0.001)$ groups when compared with controls. But retinopathy group has shown significant rise $(\mathrm{p}<0.001)$ as compared to cataract group. Such rise of serum TG with retinopathy changes is obtained by Heydari et al $2012^{21}(26.5 \%)$, Malay eye study serum cholesterol levels with the development of cataract as compared to retinopathy. Similar observation was done by Heydari et al $2012^{21}$ suggesting the role of oxysterol, an oxidative derivative of cholesterol for raised oxidative stress leading to cataract $2011^{22}$ (39.7\%), Raman et al $2010^{23}$ and Paunksnis A et al $(2007)^{24}$ (OR=1.86 [95\% CI, 1.20-2.90]) suggesting role of serum triglycerides for the raised oxidative stress responsible for retinopathy changes.

In present study, among the lipid profile, total cholesterol was significantly raised $(\mathrm{p}<0.001)$ in diabetic patients as compared to control group but there is significant rise $(\mathrm{p}<0.001)$ in cataract patients as compared to retinopathy. Thus, it suggests major role of formation.

In the present study, serum LDL $(p<0.001)$ and LDL/HDL ratio is significantly raised $(p<0.01)$ in cataract patients as compared to retinopathy patients. Similar observation was seen by D. Meyer et al (2003) $)^{25}$ which shows (p $<0.0003$ ) for LDL/HDL ratio. Role of oxidative LDL in the development of cataract is highlighted suggesting oxidative stress as a causative factor.

In present study, serum creatinine level is significantly raised $(\mathrm{p}<0.05)$ in retinopathy patients whereas no such relation was found for cataract patients. Hyperglycaemia stimulates mesangial cell matrix production and mesangial cell apoptosis. AGEs in various tissues attach to collagen which can contribute to the associated renal and microvascular complications. ${ }^{26}$ Other factors involvedare prorenin, cytokines, profibrotic elements, inflammation and vascular endothelial growth factor ${ }^{27}$. Similar observations were seen by Haddad OA et al $(1998)^{28}$ and Niveditha $\mathrm{H}^{29}$ et al in 2013.

\section{Conclusion}

From this study, we conclude that early detection of diabetic retinopathy and cataract risk can help in decreasing the morbidity and mortality in type 2 diabetes and its related complications. Strict glycaemic control, monitoring of lipid profile, serum creatinine with better management may delay diabetic retinopathy and cataractous changes.

\section{References}

1. Gadkari SS, Maskati QB, Nayak BK. Prevalence of diabetic retinopathy in India: The All India Ophthalmological Society Diabetic Retinopathy Eye Screening Study 2014. Indian J Ophthalmol 2016 Jan;64(1):38-44.

2. American Diabetes Association Diabetes Care. 2010 Jan;33(Suppl 1):S11-S61.

3. American Diabetes Association. Diabetes Care. 2011 Jan;34(Suppl 1):S62-S69.

4. Nihat Sayin, Necip Kara, Gökhan Pekel Ocular complications of diabetes mellitus World J Diabetes. Feb 15, 2015;6(1):92-108.

5. Marshall SM, Flyvbjerg Prevention and early detection of vascular complications of diabetes.A BMJ.2006;333:475-80.

6. Plasma MDA and antioxidant vitamins in diabetic retinopathy Indian Journal of Clinical Biochemistry, 2008/23(2)158-62.

7. Murthy GV, Das T Diabetic care initiatives to prevent blindness from diabetic retinopathy in India. Indian J Ophthalmol. 2016 Jan;64(1):50-4. 
8. Zimmet P, Alberti KG, Shaw J. Global and societal implications of the diabetes impairment. Nature 2001;14:782-7.

9. Faucy As, Kasper DL, Braunwald E, Hauser SL, Longo DL, Jameson JL, Loscalzo J. Harrison's principles of internal medicine 18th edition Diabetes Mellitus. Chapter 344

10. Klein BE, Klein R, Moss MS. Prevalence of cataracts in a population-based study of persons with diabetes mellitus. Ophthalmol. 1985;92(9):1191-6.

11. Klein BE, Klein R, Moss SE Incidence of cataract surgery in the Wisconsin Epidemiologic Study of Diabetic Retinopathy. Am J Ophthalmol. 1995 Mar; 119(3):295-300.

12. Yanoff, Myron; Duker, Jay S. Textbook of Ophthalmology (3rd ed.). Edinburgh: Mosby. 2008, p. 412.

13. Thapa R, Paudyal G, Maharjan N, Bernstein PS Demographics and awareness of diabetic retinopathy among diabetic patients attending the vitreo-retinal service at a tertiary eye care centre in Nepal. Nepal J Ophthalmol 2012. 4(7):10-6.

14. Morley JE. The Elderly Type 2 Diabetic Patient: Special Considerations. Diabet. Med.1998, 15 (Suppl. 4): S41-S46.

15. Davis MD, Fisher MR, Gangnon RE, et al: Risk factors for high-risk proliferative diabetic retinopathy and severe vision loss: Early Treatment Diabetic Retinopathy Study Report 18 Invest Ophthalmol Vis Sci 1998,39(2):233-52.

16. Klein R, Klein BEK, Moss SE, Davis MD, DeMets DL. Th e Wisconsin Epidemiologic Study of Diabetic Retinopathy III. Prevalence and risk factors of Diabetic Retinopathy when age at diagnosis is 30 or more years. Arch Ophthalmol 1984, 102(4):527-32.

17. Katulanda P, Ranasinghe $P$, Jayawardena $R$. Prevalence of retinopathy among adults with selfreported diabetes mellitus: the Srilanka diabetes and cardiovascular study. BMC Ophthalmology 2014, 14(100).

18. Amy G. Huebschmann, , Judith G. Regensteiner, Helen Vlassara, and Jane E.B. Reusch, Diabetes Care 2006 Jun;29(6):1420-32

19. Streeten BW. The nature of the ocular zoonule. Trans Am Ophthalmic Soc.1982;80:823-54.

20. Hogan MJ, Alvarado JA, Weddell JE. Histology of the human eye. Philadelphia: WB Saunders. 1971.

21. B Heydari, TKazemi, AZarban, S Ghahramani Correlation of Cataract with Serum Lipids, Glucose and Antioxidant Activities a Casecontrol Study West Indian Med J 2012;61(3):2304.

22. .Sabanayagam C, Wang JJ, Mitchell P, Tan AG, Shyong Tai E. Metabolic syndrome components and age-related cataract: the Singapore Malay Eye Study. Invest Ophtholmol Vis Sci 2011;52:2397-404.

23. .Raman R, Pal SS, Adams JS, Rani PK, Vaithesswaran K, Sharma T. Prevalence and risk factors for cataract in diabetes: Sankara Nethralaya Diabetic Retinopathy Epidemiology and Molecular Genetics Study, report no. 17. IOVS 2010;51(12):6253-61.

24. .Paunksnis A Bojarskiene F Cimbalas a Cerniauskiene LR Luksiene DI Tamosiunas A.
Relation between cataract and metabolic syndrome and its components. Eur J Ophthalmol. 2007:17:605-14.

25. D. Meyer, D. Parkin, F.J. Martiz, P.H. Liebenberg Abnormal serum lipoprotein levels as a risk factor for the development of human lenticular opacities Cardiovasc J South Afr 2003;14:60-4.

26. C. Sabanayagam, A. Shankar, D. Kohetal., "Retinal microvascular calibre and chronic kidney disease in an Asian population," The American Journal of Epidemiology, 2009, vol.169, no.5, pp.625-32.

27. A.E. Raptisand G. Viberti, "Pathogenesis of diabetic nephropathy," Experimental and Clinical Endocrinology \& Diabetes, 2001, vol. 109, supplement2, pp.S424-S437.

28. Ossama A W El Haddad, Mohammed Kamal Saad Prevalence and risk factors for diabetic retinopathy among Omani diabetics Br J Ophthalmol 1998;82:901-6.

29. Niveditha H, Yogitha C, Liji P, Sundeep Shetty et al Clinical Correlation of HBA1C and Diabetic Nephropathy with Diabetic Retinopathy Journal of Evolution of Medical and Dental Sciences 2013; Vol. 2, Issue 49, December 09;Page:9430-5. 